\title{
PENGETAHUAN IBU BALITA TERHADAP PEMANFAATAN BUKU KIA
}

\author{
Julaecha $^{1)}$, Ajeng Galuh W' ${ }^{2}$, Indarmien Netty Ariasih ${ }^{3)}$ \\ ${ }^{1}$ Prodi D III Kebidanan STIKBA Jambi \\ ${ }^{2,3}$ Jurusan Kebidanan Poltekkes Kemenkes Jambi \\ email:echa_mamee@yahoo.com
}

\begin{abstract}
Mother and child are groups that are vulnerable to various health problems that cause death. The mother and child health book is a tool for recording and monitoring maternal and child health, as a communication tool between health workers and families and can be used in all health facilities. Mother Toddler Classes are followed by mothers who have children between 0-5 years of age together discussing, exchanging opinions, exchanging experiences on the fulfillment of health, nutrition, and stimulation of growth and development, which are guided by facilitators using the MCH handbook. Community service aims to determine the knowledge and participation of children under five years of age on the knowledge of the use of books and participatory participation in the classes of mothers under five. The method used in community service is the lecture method used when providing information about the importance of the use and important information to monitor the growth of children listed in the MCH handbook. Results: The process of implementing a mother class of toddlers in the village of Sungai Putri, Jambi City as a whole was good, the activities related to the implementation process of Ibu Baita's classes included evaluating ownership of MCH books, exclusive breastfeeding, immunization, giving vitamin A, weighing body and stimulation of child development and the administration of MP-ASI
\end{abstract}

Keywords: knowledge, utilization of the MCH handbook, mother toddler

\begin{abstract}
ABSTRAK
Ibu dan anak adalah kelompok yang rentan terhadap berbagai masalah kesehatan yang menyebabkan kematian. Buku kesehatan ibu dan anak merupakan alat untuk merekam dan memantau kesehatan ibu dan anak, sebagai alat komunikasi antara tenaga kesehatan dan keluarga serta dapat digunakan disemua fasilitas kesehatan. Kelas Ibu Balita diikuti oleh ibu yang mempunyai anak berusia antara 0-5 tahun secara bersamasama berdiskusi, tukar pendapat, tukar pengalaman akan pemenuhan pelayanan kesehatan, gizi, dan stimulasi pertumbuhan dan perkembangan, yang dibimbing oleh fasilitator dengan menggunakan buku KIA. Pengabdian masyarakat ini bertujuan untuk mengetahui pengetahuan serta partisipasi ibu balita terhadap pengetahuan pemanfaatan buku dan berpastisipasi dalam mengikuti kelas ibu balita. Metode yang digunakan dalam pengabdian kepada masyarakat ini adalah metode ceramah digunakan pada saat pemberian informasi mengenai pentingnya penggunaan dan informasi penting untuk memantau tumbuh kembang anak yang tertera dalam buku KIA. Hasil: Proses pelaksanaan kelas ibu balita di kelurahan Sungai Putri Kota Jambi secara keseluruhan pelaksanaanya baik, kegiatan-kegiatan yang terkait dengan proses pelaksanaan kegiatan kelas Ibu baita ini meliputi evaluasi kepemilikan buku KIA, pemberian ASI Ekslusif, pemberian Imunisasi, pemberian vitamin $\mathrm{A}$, penimbangan berat badan dan stimulasi tumbuh kembang anak serta pemberian MP-ASI
\end{abstract}

Kata Kunci: Pengetahuan; Pemanfaatan Buku KIA; Ibu Balita

\section{PENDAHULUAN}

Angka kematian bayi (AKB) dan Angka Kematian Balita (AKABA) merupakan salah satu target dalam Milenium Development Goals $(M D G$ 's) Ibu dan anak merupakan kelompok yang paling rentan terhadap berbagai masalah kesehatan yang 
menyebabkan kematian, oleh karena itu menjadi fokus utama pembangunan kesehatan. (Kemenkes RI 2016)

Anak balita adalah anak yang telah menginjak usia satu tahun atau lebih atau lebih dikenal dengan anak usia di bawah lima tahun. Saat usia balita anak masih tergantung penuh pada orangtuanya untuk melakukan kegiatan penting seperti mandi, buang air dan makan. Pertumbuhan dan perkembangan di masa ini menjadi penentu keberhasilan pertumbuhan dan perkembangan anak diperiode selanjutnya. Masa tumbuh kembang diusia ini berlangsung dengan cepat dan tidak akan terulang karena itu sering disebut dengan golden age atau masa keemasan.(Septi Fitrah Ningtyas 2016)

Upaya untuk menurunkan AKB dan AKABA di Indonesia, pemerintah perlu menggencarkan upaya promotif dan preventif. Upaya promotif dan preventif dilakukan agar adanya perubahan peningkatan pengetahuan, dan sikap setra keterampilan ibu beserta keluarga dalam meberikan asuhan kepada bayi dan balita. Program pemerintah yang dilaksanakan oleh Puskesmas untuk menjalankan funsgi tersebut adalah program kelas ibu Balita. Melalui SK No. 284/Menkes/SK/III/2004 disampaikan bahwa buku Kesehatan Ibu Anak (KIA) digunakan sebagai buku pedoman resmi yang berisi informasi dan catatan kesehatan Ibu dan Anak. (Surat Keputusan No. 284/Menkes/SK/III/2004)

Buku KIA merupakan satu-satunya alat pencatatan pelayanan kesehatan Ibu dan Anak sejak masa hamil, bersalin, nifas sampai bayi yang dilahirkan berusia lima tahun. Buku KIA diharapkan dapat meningkatkan pemahaman ibu terhadap kesehatan anak. Untuk meningkatkan pemahaman pemanfaatan buku KIA tersebut perlu diadakan kegiatan kelas Ibu Balita. Kelas ibu balita berujuan untuk dapat saling berdiskusi, bertukar pendapat, pengalaman dalam bidang pelayanan kesehatan, gizi, dan stimulasi pertumbuhan perkembangan anak. (Depkes RI, 2009).

Didukung oleh penelitian Septi Fitria Ningtyas di Mojokerto. Menunjukkan bahwa ada efek kelas Ibu Balita terhadap perilaku pemanfaatan Buku KIA. (Septi Fitrah Ningtyas, 2018)
Pengetahuan atau kognitif adalah faktor yang sangat penting dalam membentuk tindakan seseorang (overt behavior). Pengetahuan seseorang terhadap objek mempunyai intensitas atau tingkatan yang berbeda. Upaya yang dapat dilakukan agar masyarakat atau individu dapa berperilaku atau mengadopsi perilaku kesehatan adalah dengan cara persuasi, bujukan, himbauan, ajakan, memberikan informasi, memberikan kesadaran dan sebagainya melalui kegiatan antara lain dengan pendidikan kesehatan (Notoatmojo, 2009)

Sejalan dengan penelitian di Mojokerto tentang Pengaruh kelas Ibu Balita Usia 0-59 bulan terhadap pengetahuan pemanfaatan buku KIA menyatakan bahwa. Terdapat pengaruh antara kelas Ibu balita dengan pengetahuan terhadap pemanfaatan buku KIA. Pengetahuan tentang kesehatan ibu dan anak dalam buku KIA sangat lengkap, sehingga dengan adanya buku KIA maka pengetahuan ibu semakin meningkat dan dapat meningkatkan derajat kesehatan ibu dan anak dapat meningkatkan. (Septi Fitrah Ningtyas 2016)

Kelas ibu balita adalah kelas dimana para ibu yang mempunyai anak berusia 0 sampai 5 tahun secara bersama-sama berdiskusi. Tukar pendapat, tukar pengalaman akan pemenuhan pelayanan kesehata, gizi, dan stimulasi pertumbuhan dan perkembangan dibimbing oleh fasilitator dalam hal ini digunakan buku KIA. Tujuan diadakan kelas ibu balita untuk meningkatkan pengetahuan dan keterampilan, merubah sikap dan perilaku ibu yang mempunyai anak balita tentang kesehatan balita, gizi, dan stimulasi pertumbuhan dan perkembangan anak, selain itu kelas ibu balita ini merupakan program untuk memnafaatkan buku KIA dalam meningkatkan kesehatan ibu dan anak. (Kemenkes 2015)

Berdasarkan pertimbangan ini maka perlu mengajari ibu ibu tentang isi buku KIA dan cara menggunakan buku KIA, salah satunya yaitu dengan mengadakan dan mengevaluasi pelaksanaan kelas Ibu Balita, yang ditujukan bagi ibu yang mempunyai anak balita (0-59 bulan). Dibawah bimbingan fasilitator dengan menggunakan buku KIA sebagai alat atau media pembelajaran.. (Kemenkes RI 2011 


\section{TARGET DAN LUARAN}

\section{Target}

Target yang diharapkan antara lain:

1) Ibu Balita memahami tentang informasi-informasi yang terdapat dlam buku KIA sera mengaplikasikan dalam pemantauan dan pertumbuhan dan perkembangan anak

2) Peningkatan kualitas kemampuan kader posyandu dalam optimalisasi pengelolaan posyandu. Berperan aktif dalam penyiapan tempat pelaksanaan

2. Luaran

Adapun luaran dari pengabdian masyarakat tentang pelaksanaan kelas Ibu Balita diintegrasikan kedalam mata kuliah Neonatus, bayi, balita dan anak Prasekolah.

\section{METODE PELAKSANAAN}

Pelaksanaan kegiatan pada bulan Maret 2018 di kelas Ibu Balita di kelurahan Sungai Putri Kota Jambi sebagai implementasi dari tri darma Perguruan Tinggi. Metode yang digunakan adalah ceramah, diskusi tanya jawab, Metode ceramah digunakan pada saat pemberian informasi mengenai pentingnya penggunaan dan banyaknya Informasi yang penting untuk memantau tumbuh kembang anak yang tertera di dalam buku KIA.mulai dari kehamilan, persalinan, bayi baru lahir, post natal/nifas, neonatus dan tumbuh kembang anak sampai dengan anak usia pra sekolah. Metode diskusi tanya jawab dan berbagi pengalaman sesama ibu ibu yang mempunyai balita. Dalam prakteknya para ibu didorong untuk belajar dari pengalamanpengalaman ibu balita lainnya. Fasilitator berperan sebagai pengarah, bukan guru atau dosen yang mengajari, tetapi bisa menjadi salah satu sumber belajar. Alat dan Media yang digunakan pada pengabdian ini adalah LCD, Laptop, buku KIA, slide power point

\section{HASIL DAN PEMBAHASAN}

Kelas ibu balita merupakan kelas ibu yang mempunyai anak berusia 0-5 tahun, dirancang dengan metode belajar melalui diskusi, tukar pendapat dan pengalaman terkait dengan pelayanan kesehata, gizi, stimulasi pertumbuhan dan perkembangan dengan bimbingan dari fasilitator/tenaga kesehatan. Fasilitator berperan sebagai pengarah, bukan guru atau dosen yang mengajari, tetapi bisa menjadi salah satu sumber belajar. (Departemen Kesehatan, 2009)

Proses pelaksanaan kelas ibu balita di kelurahan Sungai Putri Kota Jambi secara keseluruhan pelaksanaanya baik, kegiatankegiatan yang terkait dengan proses pelaksanaan kegiatan kelas Ibu baita ini meliputi evaluasi kepemilikan buku KIA, pemberian ASI Ekslusif, pemberian Imunisasi, pemberian vitamin A, penimbangan berat badan dan stimulasi tumbuh kembang anak serta pemberian MPASI.

Buku KIA merupakan alat pencatatan kesehatan ibu dan anak, alat komunikasi antara tenaga kesehatan dengan ibu dan keluarga, alat penyuluhan (edukasi) kesehatan ibu dan anak, milik keluarga dan dapat digunakan disemua fasilitas kesehatan. Pemanfaatan buku KIA ini merupakan salah satu program prioritas di Indonesia, karena melalui penerapan buku KIA ini akan fokus catatan pada pelayanan kelompok penduduk paling rawan (ibu hamil dan balita) berdampak positif bagi kesehatan dan perkembangan anak usia dini sejak dalam kandungan ibu sampai berumur lima tahun, dan mendukung upaya pencegahan dan deteksi dini masalah kesehaan dan gizi ibu dan anak ditingkat keluarga. (Ernoviana, 2005)

Didukung oleh penelitian Lia Aria Ratnawati tentang evaluasi program pelaksanaan kelas ibu balta di wilayah kerja dinas kesehatan Kabupaten Banjarnegara menyatakan bahwa hasil penyelenggaraan kelas balita meliputi beberapa item penilaian pre test dan post test peserta antara lain $58,41 \%$ nilainya meningkat, 32,11 nilainya tetap dan $9,48 \%$ nilainya menurun.(Lia Artika Rahmawati 2018) 

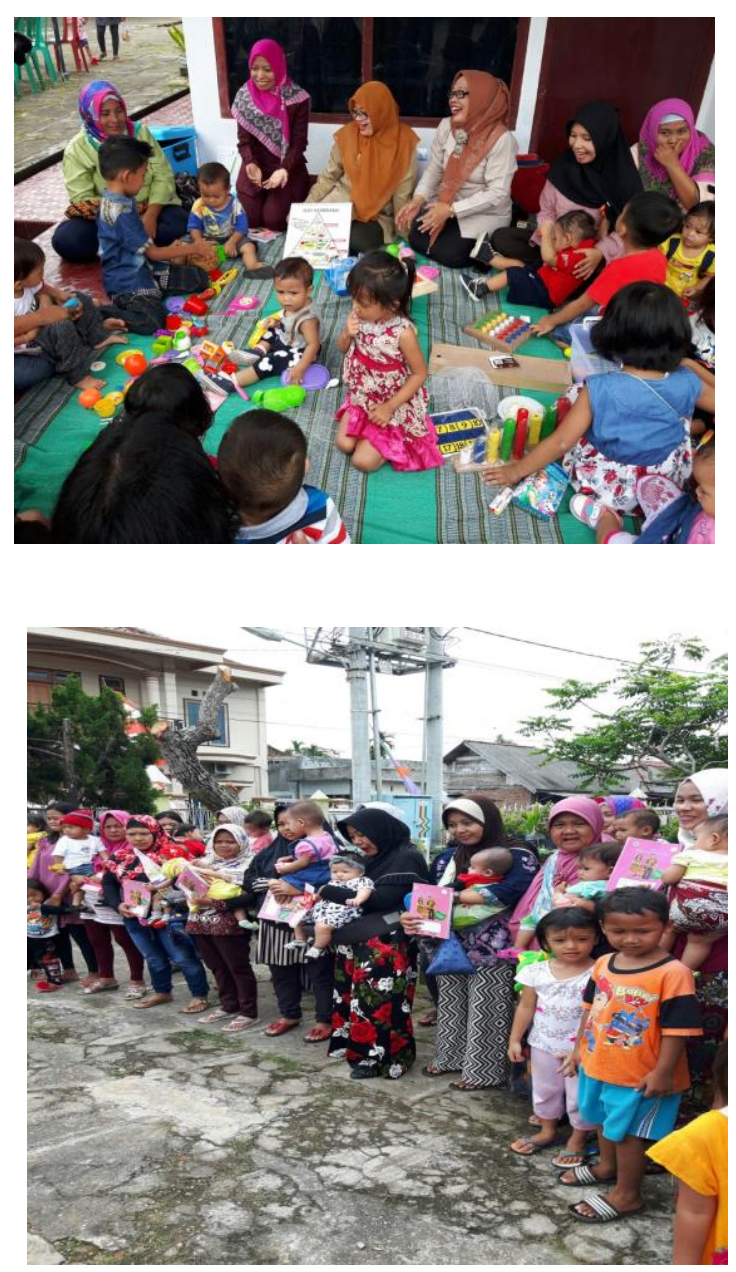

\section{KESIMPULAN DAN SARAN}

\section{Kesimpulan}

Pelaksanaan kegiatan pengabdian kepada masyarakat, pelaksanaan kelas Ibu Balita di Kelurahan Sungai Putri Kota Jambi, secara umum dapat disimpulkan bahwa terdapat peningkatan pengetahuan pemanfaatan buku KIA oleh Ibu Balita. Penilaian pelaksanaan kelas Ibu Balita di Kelurahan Sungai Putri tidak dilakukan pre tes dan post test. Penilaian peningkatan pengetahuan ibu balita hanya dengan tanya jawab dan diskusi, sehingga tidak dapat menilai peningkatan pengetahuan ibu balita tentang materi yang telah disampaikan.

\section{Saran}

Disarankan kepada buat kader posyandu balita yang telah ada di aktifan kembali dan setiap kader mendapat reward atau ada perlombaan kader di setiap kelurahan di wilayah kerja Puskesmas atau tingkat nasional sebagai bentuk motivasi kader dalam mengabdikan diri untuk kemajuan kesehatan di wilayahnya, dalam upaya meningkatkan pengetahuan dan dan keterampilan kader perlu adanya pelatihan, penyuluhan, dan pendampingan.

\section{UCAPAN TERIMAKASIH}

Terima kasih kepada Bapak Ketua Sekolah Tinggi Ilmu Kesehatan Baiturrahim Jambi yag telah memberikan dana dan Bapak ketua RT 17, 26, 25 kelurahan Sungai Putri Kota Jambi yang telah memberikan izin dan memfasilitasi kegiatan pengabdian masyarakat ini.

\section{DAFTAR PUSTAKA}

Septi Fitrah Ningtyas. Pengaruh kelas ibu balita usia 0-59 bulan terhadap pengetahuan pemanfaatan Buku KIA. Jurnal keperawatandan kebidanan-STIKes Dian Husada Mojokerto. Tahun 2016

Permenkes SK No. 284/Menkes/SK/III/2004 disampaikan bahwa buku Kesehatan Ibu Anak (KIA) digunakan sebagai buku pedoman resmi yang berisi informasi dan catatan kesehatan Ibu dan Anak.

Departemen Kesehatan RI 2009. Pedoman pelaksanaan Kelas Ibu Balita Jakarta.

Kemenkes RI 2011., Pedoman Penyelenggaraan Kelas Ibu Balita, Ibu Hamil, dan menyusui Jakarta, Nice Project

Notoatmodjo, S.2007 Promosi Kesehatan dan Ilmu Perilaku. Jakarta. Rineka 
Jurnal Abdimas Kesehatan (JAK) Vol 1,No.2, Juni 2019

p-ISSN :2655-9226

e-ISSN: 2655-9218

Adevia Maulidya, Budi laksono, Ari Yuniastuti. Efektifitas SMS Bunda dibandingkan kelas ibu Balita Terhadap Peningakatan Pengetahuan, Sikap dan perilaku. Public Health Perspective Journal I(1)(2016)

Lia Artika Rahmawati 2018, Evaluasi program pelaksanaan kelas Ibu Balita diwilayah kerja dinas Kesehatan Kabupaten Banjarnegara. Jurnal kebidanan dan keperawatan Aisyiyah, vol 14, No.1 Juni 2018

Ernoviana M.H 2005 Pemanfaatan Buku Kesehatan Ibu dan Anak di Dinas Kesehatan Kota 